\title{
Hydraulic Research for Lateral Plant Obstruction in an Open Channel
}

\author{
Tomasz Tymiński ${ }^{1}, \mathrm{Krzysztof} \mathrm{Wolski}^{1 *}$, Maciej Gruszczyński ${ }^{1}$, \\ Xia Jianxin², Ren Huatang ${ }^{2}$, Yao Nijun ${ }^{2}$ \\ 1 Wrocław University of Environmental and Life Sciences, Institute of Environmental Engineering, \\ Plac Grunwaldzki 24, 50-363 Wrocław, Poland \\ 2 Minzu University of China, Institute of Environment \& Resources Protection for Minority Areas, \\ 27 Zhong-Guan-Cun, Beijing 100081, China \\ * Corresponding author's e-mail: krzysztof.wolski@upwr.edu.pl
}

\begin{abstract}
The hydraulic model testing results of flow of a water stream through a lateral plant obstruction are presented in the paper. The plant element was formed by natural deciduous and coniferous tree branches filling the space between tree trunks set in chequered pattern. The experiments conducted in a horizontal, rectangular hydraulic channel included the measurements of flow intensity, difference in water surface level before and after the obstruction and filling of the channel on the upstream and downstream sides. A preliminary analysis of results was performed determining the coefficient of local losses of lateral plant obstruction. The coefficient of water discharge for the fascine overfall case assumed for the plant obstruction was determined as well.
\end{abstract}

Keywords: fascine overfall, coefficient of discharge, local resistances, damming up.

\section{INTRODUCTION}

The ever increasing application of plant build up in stream channels encourages to seek more perfect calculating methods taking into consideration the reaction of plants to flow in open channels (Chow, 1959; Tsujimoto, 1999; Järvelä, 2004; Gurnell, 2015; Solari et al., 2016; RadeckiPawlik et al., 2017; Kałuża et al., 2018). The biological reaction of channel build up on the flow conditions is characterized among others, by damming up (accumulation) effect (change in water surface level), increase in flow resistance, decrease in flow capacity of the channel, etc. (Chow, 1959; Dąbkowski and Pachuta, 1996; Tymiński and Kałuża, 2012; Wolski et al., 2018). One of the ways enabling the study of such hydraulic reactions of plants are laboratory investigations (Tal and Paola, 2010; Västilä and Järvelä, 2014; Ebrahimi et al., 2017). Nowadays, little is still known about that problem. There is not enough field or laboratory data available. An important contribution are the classic investigations by Klaassen and van der Zwaard (Klaassen and Van Der Zwaard, 1974).

In the paper, a hydraulic characteristic test of plant obstruction situated laterally to the direction of water flow, was undertaken. Such a situation occurs in broad obstructions of stream channels, or during flow into polders. In such cases, water accumulations occur above the obstruction (Klaassen and Van Der Zwaard, 1974). The hydraulic characteristic of the plant obstruction could be the coefficient of local losses if we treat the plant element as the local linear obstruction or the overflow water discharge coefficient, and when we treat the obstruction as the overflow. In such a case, this overflow can be called a fascine overfall.

\section{MATERIAL AND METHODS}

The experimental investigations were performed in the water laboratory of Franzius Institute at the University in Hannover. Figure 1 
shows a general schematic of the measurement set-up together with the supply installation.

The test model consisted of a straight rectangular channel with the length of $20 \mathrm{~m}$ and width of $0.98 \mathrm{~m}$. The channel walls were made of glass and the horizontal, flat bottom was a PVC board. The maximum depth of the channel was $0.85 \mathrm{~m}$. The total delivery of the pumps supplying the model amounted to $0.22 \mathrm{~m}^{3} \mathrm{~s}^{-1}\left(2201 \cdot \mathrm{s}^{-1}\right)$. The water surface level drop was measured as the difference of readings of two Wavo type limnigraphs (manufacturer: Delft Hydraulics Laboratory) located in the channel axis at a definite distance from each other. The filling of the channel was additionally checked on the water gauges along the measuring section and regulated with a movable regulating overfall provided with a scale and localized at the outlet of the channel. Water was supplied from a top equalizing tank through a steel pipeline with the diameter of $300 \mathrm{~mm}$. A MAG-X Plus type induction flow meter (manufacturer: Fischer\&Porter) and sluice valve with servo control were installed on the pipeline.

The plant element under study is presented in Figures 2 and 3. The characteristic quantities amounted to: diameter of tree trunks $d_{p}=0.10 \mathrm{~m}$, spacing $a_{x}=0.35 \mathrm{~m}, a_{z}=0.20 \mathrm{~m}$. the free space between the trunks arranged in a chequered pattern was filled with deciduous and coniferous tree branches. The plant element under study

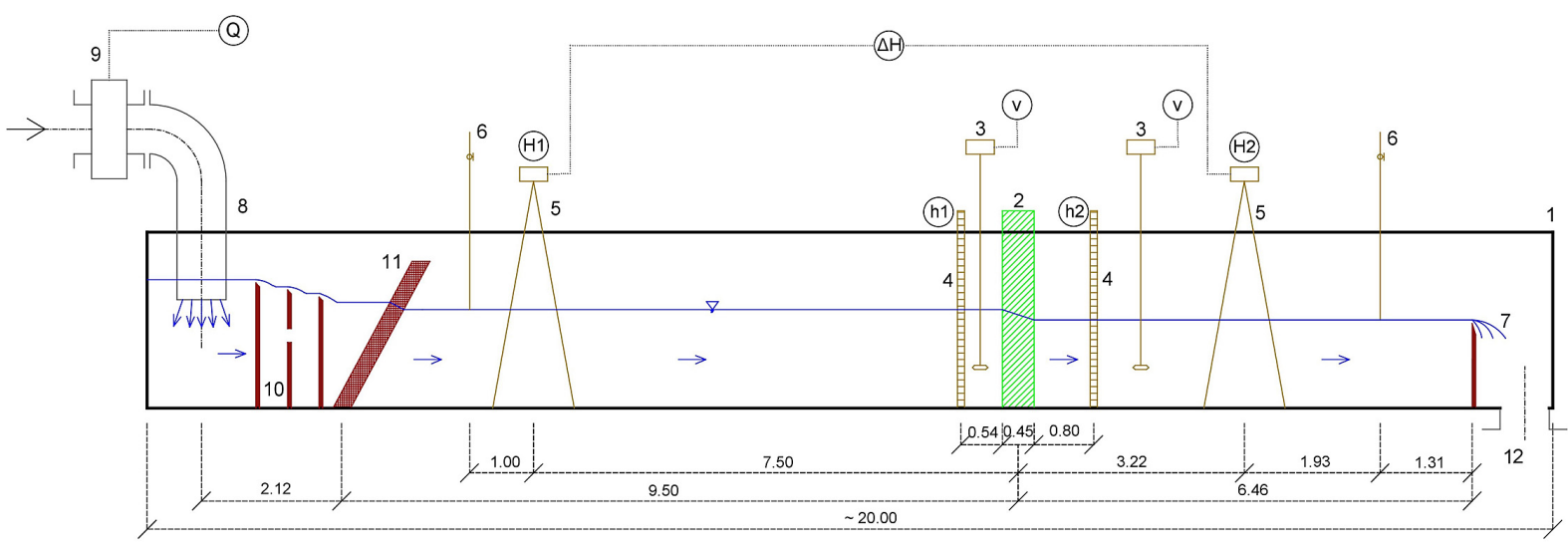

Figure 1. Schematic view of the measurement set-up:

1 - rectangular channel: $\mathrm{b} \times \mathrm{h}=0.98 \times 0.85 \mathrm{~m}, 2$ - plant element construction, 3 - induction probe for velocity measurement, 4 - water-level gauge, 5 - limnigraph, 6 - needle-type water-level gauge, 7 - adjustable overfall,

8 - supply pipeline, 9 - induction flow-through meter, 10 - flow calming barrier, 11 - flow calming net
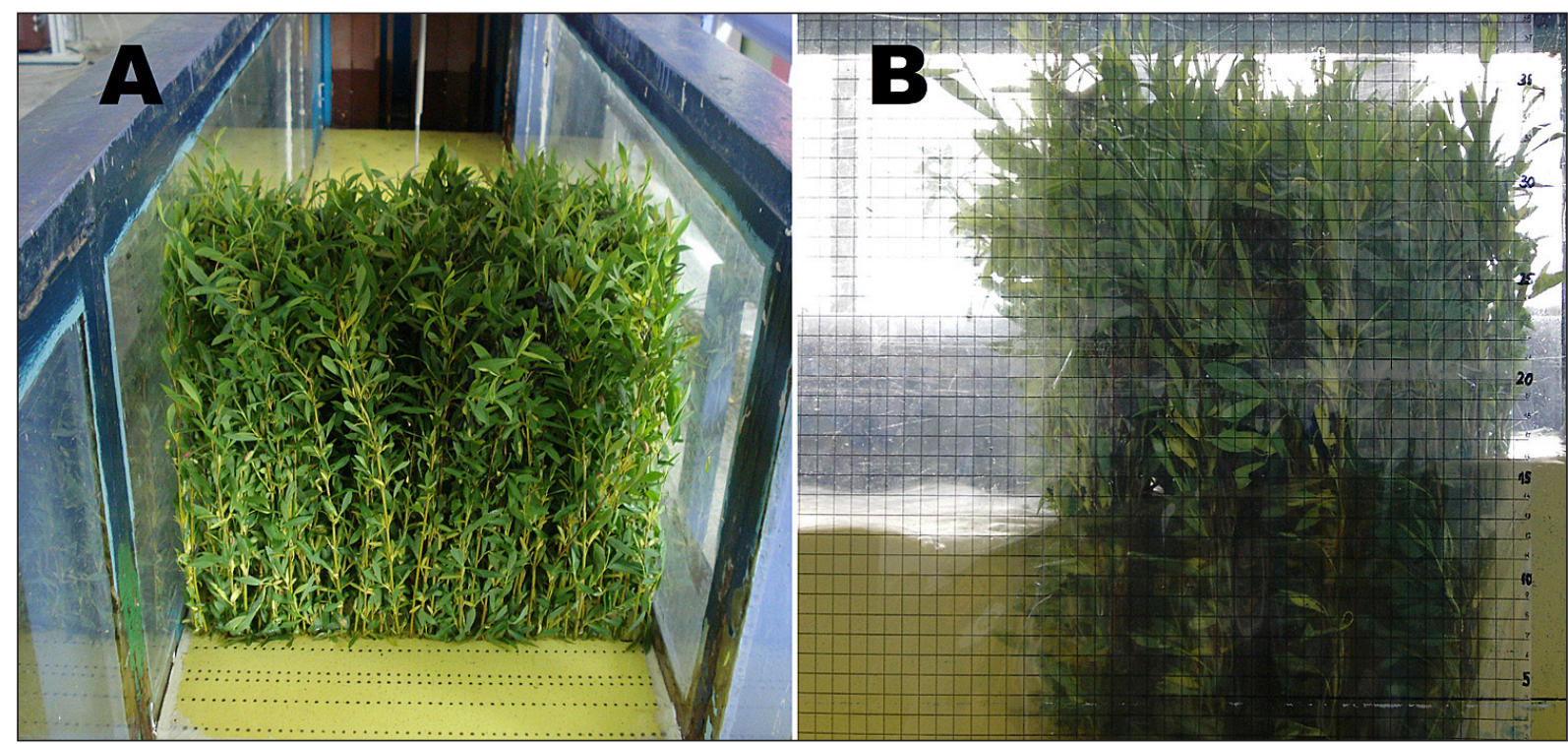

Figure 2. View of a lateral plant obstruction located in a laboratory channel: A) along the direction of water flow, B) perpendicular to the direction of water flow 
(trees + branches) screened $78.5 \%$ of the flow cross-section area.

The scope of experimental investigations included the following partitions of variables: $Q=20 \div 1601 \cdot \mathrm{s}^{-1}$, filling $H=20 \div 60 \mathrm{~cm}$. Change in value of the pair $(Q ; H)$ was set on the assumed basis, theoretical flow curve of the laboratory channel. the previously calibrated positions of the adjustable overfall at the outlet from the channel were corresponding to the water surface level $\operatorname{drop}(I=0.00021)$.

Apart from the measurements of flow intensity $Q$, the depth before $\left(H_{g}\right)$ and after $\left(H_{d}\right)$ the plant obstruction and the difference of water surface level $(\Delta H)$, the water temperature was also measured for each set of measurements. The results of the measurements obtained and their elaboration are presented below. Data labeling on a schematic calculation system is presented in Figure 4 (explanation under the equations).

\section{RESULTS AND DISCUSSIONS}

\section{Plant element as a fascine overfall}

The lateral plant obstruction in the laboratory channel was considered as a kind of fascine overfall. The characteristic determined experimentally $\mathrm{Q}=\mathrm{f}(\Delta \mathrm{H})$ of such an overfall is presented in Figure 5. The fascine overfall discharge of the parameters described above, can be defined from the universally applied formula (Finnemore and Franzini, 2009):

$$
Q=m \cdot b \cdot \sqrt{2 g} \cdot H^{3 / 2} \quad\left[\mathrm{~m}^{3} \cdot \mathrm{s}^{-1}\right]
$$

where: $m$ - coefficient of overfall discharge [-];

$b$ - overfall width [m];

$g-$ acceleration due to gravity $\left[\mathrm{m} \cdot \mathrm{s}^{-2}\right]$;

$H$ - "thickness of overflowing water layer", here $H=\Delta H$ (difference of water surface level ahead of and behind the obstruction $[\mathrm{m}]$.

Table 1 presents an example of measurement results and the coefficients determined on their basis, of the discharge of the tested overfall taking into consideration $/ \mathrm{m}(\mathrm{v}) /$ and not considering $/ \mathrm{m} /$ flow velocity ahead of the obstruction $v(g)$ (Finnemore and Franzini, 2009). The coefficient of discharge $m$ of the tested fascine overfall for flows in the inflow channel characterized by Reynolds number $R e>50000$ steadies at certain

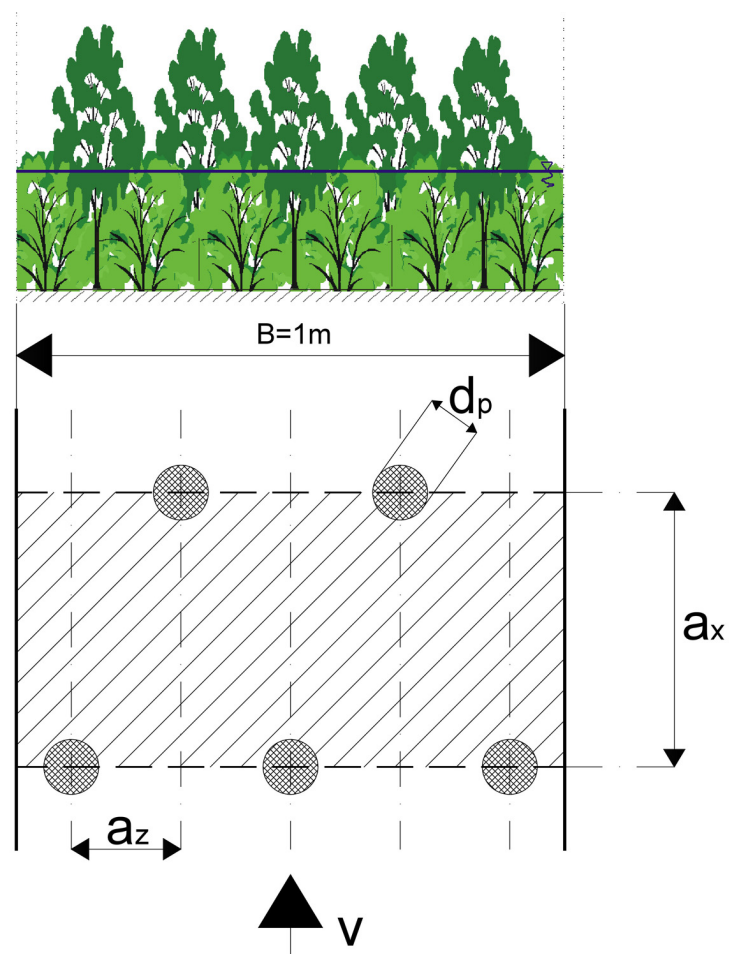

Figure 3. The distribution of vegetation in an obstacle, (crosshatching are deciduous and coniferous tree branches, darker circles of tree trunks)

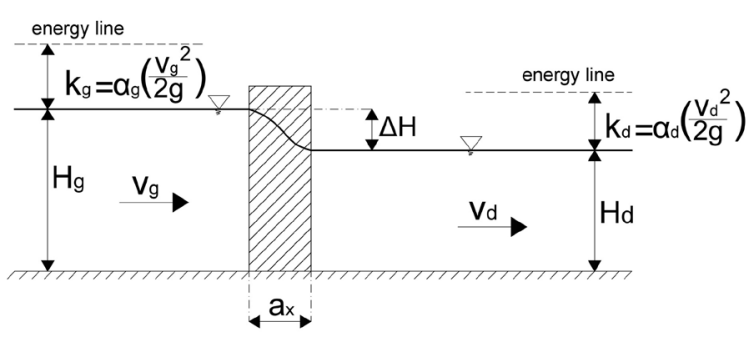

Figure 4. Data labeling on a schematic calculation system (explanation under the equations)

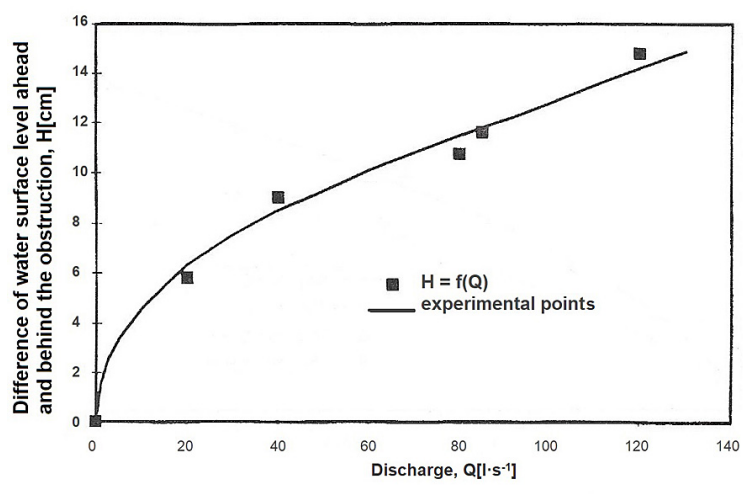

Figure 5. Experimental measurements of $Q$ and $H$ relations and characteristic curve $\mathrm{H}=\mathrm{f}(\mathrm{Q})$ 
Table 1. Sample results of measurements

\begin{tabular}{|c|c|c|c|c|c|c|c|c|c|}
\hline$Q$ & $\Delta H$ & $H(d)$ & $H(g)$ & $v(g)$ & $v(d)$ & $m$ & $m(v)$ & $h_{M}$ & $\zeta$ \\
\hline $\mathrm{I} \cdot \mathrm{s}^{-1}$ & $\mathrm{~cm}$ & $\mathrm{~cm}$ & $\mathrm{~cm}$ & $\mathrm{~m} \cdot \mathrm{s}^{-1}$ & $\mathrm{~m} \cdot \mathrm{s}^{-1}$ & - & - & $\mathrm{cm}$ & - \\
\hline 20 & 5.8 & 14.2 & 20 & 0.102 & 0.144 & 0.33 & 0.33 & 0.057 & 53.9 \\
\hline 40 & 9.0 & 21.0 & 30 & 0.136 & 0.194 & 0.34 & 0.34 & 0.089 & 46.4 \\
\hline 60 & 9.3 & 30.7 & 40 & 0.153 & 0.199 & 0.49 & 0.48 & 0.092 & 45.6 \\
\hline 80 & 9.8 & 40.2 & 50 & 0.163 & 0.203 & 0.49 & 0.48 & 0.097 & 46.3 \\
\hline 85 & 11.6 & 40.4 & 52 & 0.167 & 0.215 & 0.49 & 0.48 & 0.115 & 48.8 \\
\hline 120 & 14.8 & 45.2 & 60 & 0.204 & 0.271 & 0.49 & 0.48 & 0.146 & 39.1 \\
\hline
\end{tabular}

Where: $\mathrm{Q}$ - flow intensity; $\Delta \mathrm{H}$ - difference in water surface level (damming up/accumulation); $\mathrm{H}$ - depth; $\mathrm{v}-$ mean velocity; $\mathrm{m}$ - coefficient of overfall discharge; $\mathrm{h}_{\mathrm{M}}$ - local resistances (local energy lost); $\zeta$ - coefficient of local resistances; index: $\mathrm{g}$ - upstream water; $\mathrm{d}$ - downstream water.

level (Figure 6) and is a constant quantity. For Reynolds number $R e<50$ 000, the coefficient $m$ decrease with the decrease of value of $R e$.

\section{Coefficient of local resistances of lateral plant barrier}

In the case under consideration, the plant element under study is treated as a local linear cluster of plants, e.g. at an inter-embankment. For this type of plant obstruction described above, the coefficient of local resistances $\zeta$ was determined.

Assuming the Bernoulli equation for cross-sections before and after the obstruction (Figure 4) (Chow, 1959; Järvelä, 2004):

$H_{g}+\frac{\alpha_{g} v_{g}^{2}}{2 g}=H_{d}+\frac{\alpha_{d} v_{d}^{2}}{2 g}+\Sigma h_{s t r}[\mathrm{~m}]$

where: $\alpha_{g}=\alpha_{d}=\alpha ; \Delta H=H_{g}-H_{d} ; \sum h_{s t r}=h_{M}$

The local loss of energy (local resistance $h_{M}$ ) can be determined on the plant element under

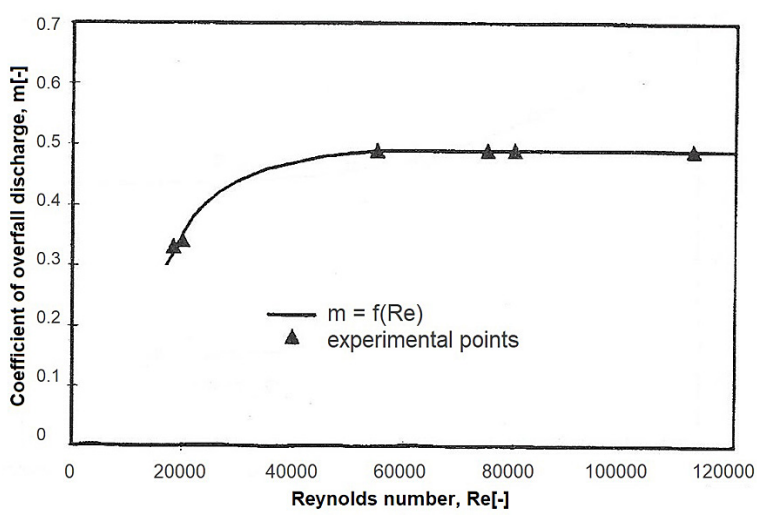

Figure 6. The relationship between coefficient of overfall discharge (m) and Reynolds number (Re) investigation as also the coefficient of local resistances $\zeta$ (Table 1) characterizing it.

$$
\begin{array}{cc}
h_{M}=\Delta H+\frac{\alpha\left(v_{g}^{2}-v_{d}^{2}\right)}{2 g} & {[\mathrm{~m}]} \\
h_{M}=\zeta \frac{v_{d}^{2}}{2 g} & {[\mathrm{~m}]}
\end{array}
$$

hence:

$$
\zeta=\frac{2 g \Delta H+\alpha\left(v_{g}^{2}-v_{d}^{2}\right)}{v_{d}^{2}}
$$

where: $\alpha$ - the St. Venant's coefficient [-];

$H_{g}$ and $H_{d}$ - water depth ahead of and behind the obstruction $[\mathrm{m}]$;

$\Delta H=H_{g}-H_{d}[\mathrm{~m}]$;

$h_{M}-$ local energy losses [m];

$g$ - acceleration due to gravity $\left[\mathrm{m} \cdot \mathrm{s}^{-2}\right]$;

$v_{g}$ and $v_{d}$ - mean flow velocity ahead of and behind the obstruction $\left[\mathrm{m} \cdot \mathrm{s}^{-1}\right]$.

Figure 7 depicts the flow curve obtained from the measurements: channel without plants $H=f(Q)$ and the channel built in plant zone $H=f(Q)$. For the examined partition of flow variables $Q$ (Figure 7), resulting from them is the drop in the channel flow capacity reaching $30.3 \%(\Delta Q)$. For example, the plant element under investigation at unit flow $q=0.122 \mathrm{~m}^{2} \cdot \mathrm{s}^{-1}\left(Q=1201 \cdot \mathrm{s}^{-1}\right)$ causes change in water surface level in the channel reaching up to $32 \%$ (damming up effect).

The variability of the coefficient of local resistances $\zeta$ of the plant element under investigation depending on the Reynolds numbers $\zeta=f(R e)$ is presented in the appended Figure 8. 


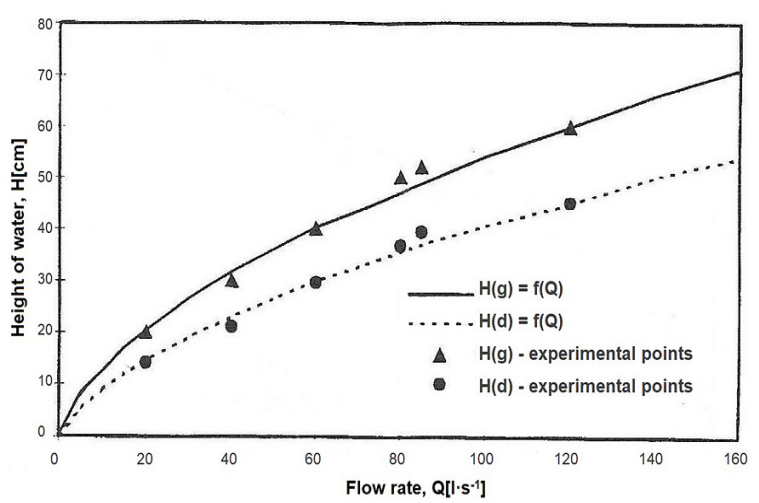

Figure 7. Flow rate curve $h=f(Q)$ for the lower station $\mathrm{H}_{\mathrm{d}}$ and the upper station $\mathrm{H}_{\mathrm{g}}$

\section{CONCLUSIONS}

The preliminary analysis of measurement results shows that the water damming up caused by local linear plant obstruction can be determined with two methods. First - through the coefficient of local losses, second - through the coefficient discharge over a fascine overfall. Knowing the values of the above-mentioned coefficients, determined during the experiment, damming up can be determined in an inter-embankment or on inundated areas by utilizing the flow discharge equation or the formula for local losses of energy.

The presented hydraulic investigation results for the lateral plant obstruction in an open channel increase the knowledge in this scientific area. However, the results of the studies form the starting basis for the further analyses and research work.

\section{REFERENCES}

1. Chow V. Ten. 1959. Open-Channel Hydraulics. McGraw-Hill Book Company, New York and London.

2. Dąbkowski, S.L., Pachuta, K.. 1996. Roślinność i hydraulika koryt zarośniętych. Wydawnictwo IMUZ, Falenty [in Polish].

3. Ebrahimi, N., Gharibreza, M., Hosseini, M.. 2017. Experimental study on the impact of vegetation coverage on flow roughness coefficient and trapping of sediment. Geology, Ecology, and Landscapes, 1(3), 167-172

4. Finnemore, E.J., Franzini, J.B.. 2009. Fluid mechanics with engineering applications. McGrawHill, Boston.

5. Gurnell, A., 2015. Plants as river system engineers: Further comments. Earth Surf. Process. Landforms 40, 135-137.

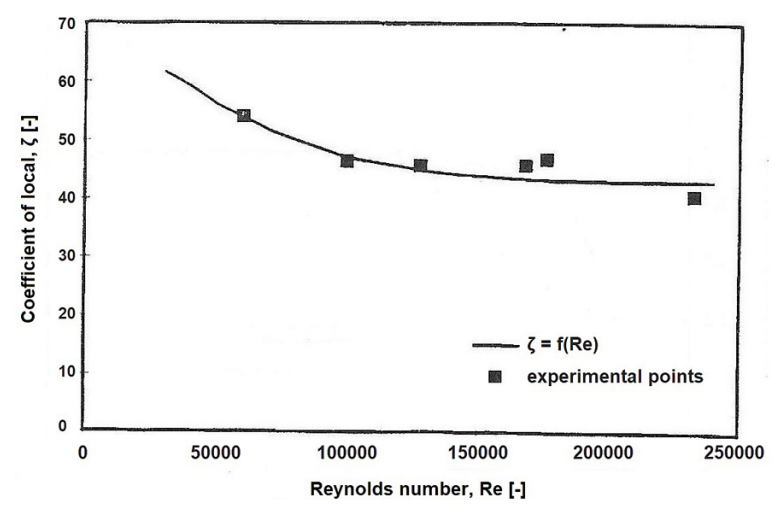

Figure 8. The relationship between coefficient of local resistances $(\zeta)$ and Reynolds number $(\mathrm{Re})$

6. Järvelä, J., 2004. Flow resistance in environmental channels: focus on vegetation. Ph.D. Thesis, Department of Civil and Environmental Engineering $\backslash$ Laboratory of Water Resources,Helsinki University of Technology $\backslash$ Aalto University Schools of Technology

7. Kałuża, T., Radecki-Pawlik, A., Szoszkiewicz, K., Plesiński, K., Radecki-Pawlik, B., Laks, I. 2018. Plant basket hydraulic structures (PBHS) as a new river restoration measure. Sci. Total Environ. 627, 245-255.

8. Klaassen, G.J., Van Der Zwaard, J.J. 1974. Roughness Coefficients Of Vegetated Flood Plains. J. Hydraul. Res. 12, 43-63.

9. Radecki-Pawlik, A., Pagliara, S., Hradecky, J. 2017. Open Channel Hydraulics, River Hydraulic Structures and Fluvial Geomorphology, 1st Editio. ed. CRC Press, Boca Raton.

10. Solari, L., Oorschot, M. Van, Belletti, B., Hendriks, D., Rinaldi, M., Vargas-Luna, A., 2016. Advances on Modelling Riparian Vegetation-Hydromorphology Interactions. River Res. Appl. 32, 164-178.

11. Tal, M., Paola, C., 2010. Effects of vegetation on channel morphodynamics: Results and insights from laboratory experiments. Earth Surf. Process. Landforms 35, 1014-1028.

12. Tsujimoto, T., 1999. Fluvial processes in streams with vegetation. J. Hydraul. Res. 37, 789-803.

13. Tymiński, T., Kałuża, T., 2012. Investigation of mechanical properties and flow resistance of flexible riverbank vegetation. Polish J. Environ. Stud. 21, 201-207.

14. Västilä, K., Järvelä, J., 2014. Modeling the flow resistance of woody vegetation using physically based properties of the foliage and stem. Water Resour. Res. 50, 229-245.

15. Wolski, K., Tyminski, T., Dabek, P.B., 2018. Assessment of the effect of vegetation on the transition of the flood wave using hydraulic 2D models. Proc. E3S Web Conf. 44. 00195 